\title{
Effect of organic calcium supplements on the technological characteristic and sensory properties of gluten-free bread
}

\author{
Urszula Krupa-Kozak • Agnieszka Troszyńska • \\ Natalia Bączek • Maria Soral-Śmietana
}

Received: 21 October 2010/Revised: 14 December 2010/Accepted: 18 December 2010/Published online: 9 January 2011

(C) The Author(s) 2011. This article is published with open access at Springerlink.com

\begin{abstract}
In the present study, the effect of individual and combined addition of two organic calcium supplements, calcium caseinate and calcium citrate to the gluten-free formulation on selected technological parameters, calcium content and sensory quality of bread was evaluated. Standard technological tests and texture analysis were performed on the gluten-free control and gluten-free breads fortified with calcium. Quantitative descriptive analysis (QDA) was used to determine differences in the sensory characteristics of the breads. Calcium citrate demonstrated the ability to increase significantly the specific volume of the breads $(p<0.05)$. Application of both calcium salts produced fine-coloured bread crust. Significant enrichment in calcium $(p<0.05)$ was obtained in gluten-free breads fortified with high amount of calcium citrate. Experimental breads, regardless the kind of calcium salt added, were rather crumbly. However, in comparison with unfortified control, the crumbs of calcium-fortified breads were softer and more elastic. Palatability of gluten-free breads supplemented with calcium was significantly higher than those of unfortified control $(p \leq 0.05)$. The desirable sensory attributes for the consumers such as the sweet odour, butterbread odour, butterbread taste as well as springiness of breads increased with the increasing addition of calcium
\end{abstract}

\footnotetext{
U. Krupa-Kozak $(\varangle) \cdot$ N. Bączek · M. Soral-Śmietana Department of Chemistry and Biodynamics of Food, Institute of Animal Reproduction and Food Research of the Polish Academy of Sciences, Tuwima St., 10, 10-747 Olsztyn, Poland

e-mail: u.krupa-kozak@pan.olsztyn.pl

A. Troszyńska

Sensory Laboratory, Institute of Animal Reproduction and Food Research of the Polish Academy of Sciences, Tuwima St., 10, 10-747 Olsztyn, Poland
}

caseinate and calcium citrate. Summarising, analysed technological properties, calcium content and sensory characteristic of experimental gluten-free breads were favourably modified by applied organic calcium salts. It suggests that they could be successfully used in gluten-free recipes allowing to obtain good-quality product.

Keywords Organic calcium supplements · Gluten-free formulation - Bread - Technological characteristic . Sensory properties

\section{Introduction}

Celiac disease $(\mathrm{CD})$ is an immune-mediated enteropathy occurred in genetically predisposed individuals. The environmental cause of this disease is dietary gluten from wheat and similar proteins from rye and barley. Originally, $\mathrm{CD}$ was thought to occur rarely in childhood, while currently it is recognised as a disorder diagnosed at any age, affecting roughly $1 \%$ of the world's population [1-3]. Such a rate establishes celiac disease as one of the most common diseases. The keystone of CD management is exclusion of gluten from the diet. However, a gluten-free diet is extremely difficult to adhere to due to the ubiquity of gluten in human foods. Besides, many patients exhibit incomplete recovery on a gluten-free diet $[4,5]$.

Gluten is a complex mixture of gliadin and glutenin proteins found in wheat and related cereals. Due to the unique viscoelastic properties, gluten plays multiple roles in the majority of baked products. Gluten contributes to batter emulsification and viscoelasticity, provides cohesiveness to dough during processing, retains leavening gases, sets the crumb structure and imparts elasticity to the bread texture. Therefore, the replacement of gluten and 
formulation of high-quality gluten-free baked products is a major technological challenge. The quality of baked gluten-free products is low; they exhibit crumbling texture, poor mouth feel, colour and flavour [6]. To overcome the problem with the lack of viscoelasticity, hydrocolloids [7, 8], starches [9] and pseudocereals [10] were incorporated in the recipes of fermented gluten-free products. Pectins due to their gelling properties are also widely used in gluten-free products as thickening and gelling agent. Also aggregated casein-based ingredient fortified with calcium could form gel network resembling gluten network [11]. Moroni et al. [12] proven that sourdough technology could be a potential tool to improve the quality of gluten-free bread.

However, poor structure and texture are not the only problem of gluten-free products. The diet and gluten-free products are characterised by a low content of nutritional components, microelements and vitamins [13, 14]. Among common deficiencies associated with a gluten-free diet, calcium deficiency is the well-known disorder. In patients with symptomatic CD, low bone density appears to be directly related to the intestinal malabsorption. Osteomalacia or osteopenia are secondary to the reduced calcium absorption, caused by atrophy of the intestinal villi, and/or to a vitamin D deficiency, leading to secondary hyperparathyroidism [15]. Osteoporosis is therefore a frequent complication accompanying celiac disease [16]. The increasing part of the products in the food industry is fortified with calcium, especially dairy products followed by beverages and snacks. Whereas, very few gluten-free products are enriched as are wheat-containing products [17]. The development of such products may possibly improve its nutritional quality and could be a useful adjunct therapy to the diet. There is some evidence to support the hypothesis that increased calcium intake might reduce the risk of suffering from osteoporosis, hypertension and kidney stones $[18,19]$; however, the cause of these diseases is multifactor and poorly understood.

Calcium is an essential nutrient required in substantial amounts, but many diets are deficient in calcium making supplementation necessary or desirable. Multiple forms of calcium supplements are available [20]. The selection of the appropriate salt for a specific application is usually based on the consideration of a number of properties associated with the respective product such as solubility, calcium content, taste and bioavailability. Calcium carbonate and calcium citrate are the main calcium salts added to foods in order to enhance the nutritional value. It has been reported that calcium as citrate is better absorbed than calcium as carbonate, causing a greater rise in serum calcium and a greater fall in serum parathyroid hormone (PTH) [21, 22]. Moreover, calcium as citrate is absorbed regardless of gastric acidity; thus, persons producing less gastric acids or receiving drugs lowering acidity in the stomach, like proton pump inhibitors [23], $\mathrm{H}_{2}$ blockers, antacids and anticholinergics, may utilise this salt form optimally. Calcium from dairy products is also readily absorbed and such products are considered as a good source of calcium. Dairy ingredients have been used in the production of gluten-free bread resulting in nutritional and functional benefits such as increased protein and calcium content, flavour and texture enhancement, and shelf-life extension [24, 25]; however, not all celiac patients tolerate dairy products (lactose-intolerant).

Up to now, research studies related to gluten-free baked products have been focused on the development of new gluten-free formulas based on combining different starches, functional ingredients and/or gluten-free pseudocereals resulting in good texture quality and prolonged shelf-life of gluten-free bakery products. However, no special attention has been brought to the use of those products as carriers or vehicles of mineral compounds. The objectives of this study were (a) to produce gluten-free bread fortified with calcium using selected calcium salts, (b) to evaluate the quality of obtained product and (c) to test the sensory characteristics of calcium-fortified breads.

\section{Materials and methods}

\section{Ingredients}

Corn starch (AgroTrade, Warsaw, Poland), potato starch (Potato-Processing Industry S.A. Niechlów, Poland), pectin (E 440(i), ZPOW Pektowin, Jasło, Poland), sunflower oil (ZPT Warsaw, Poland), fresh yeast (Lesaffre Polska S.A., Wołczyn, Poland), sugar, salt and deionised water were the basic ingredients of gluten-free bread. The organic calcium supplements used were calcium caseinate (PHZ SM Lacpol, Murowana Goślina, Poland) and calcium citrate (E 333(iii), Hortimex, Konin, Poland) [26].

\section{Breadmaking process}

The gluten-free breads formulation is showed in Table 1. Main solid ingredients were mixed together for $5 \mathrm{~min}$ at minimum speed using a KitchenAid Professional K45SS mixer (KitchenAid Europa, Inc, Brussels, Belgium) in the stainless steel bowl with flat beater. Yeast was dissolved in water and added to the dry mixture together with oil. The batter was mixed for $12 \mathrm{~min}$. A 240-g sample of the resulting batter was placed in a greased baking tins and rested in a proofer at $35{ }^{\circ} \mathrm{C}$ and $70 \%$ relative humidity for 40 min. Baking was then carried out for $30 \mathrm{~min}$ at $220^{\circ} \mathrm{C}$ top and bottom in the laboratory oven (ZBPP, Bydgoszcz, Poland) previously steamed. Bread after baking was cooled 
Table 1 Gluten-free breads formulation

\begin{tabular}{|c|c|c|c|c|c|c|}
\hline Ingredients (\%) & Control & CAS & CIT & CAS1/CIT1 & CAS1.3/CIT0.7 & CAS0.7/CIT1.3 \\
\hline Corn starch & 36.7 & 36.7 & 36.7 & 36.7 & 36.7 & 36.7 \\
\hline Potato starch & 8.9 & 8.9 & 8.9 & 8.9 & 8.9 & 8.9 \\
\hline Pectin & 2.2 & 2.2 & 2.2 & 2.2 & 2.2 & 2.2 \\
\hline Sugar & 2.8 & 2.8 & 2.8 & 2.8 & 2.8 & 2.8 \\
\hline Salt & 0.8 & 0.8 & 0.8 & 0.8 & 0.8 & 0.8 \\
\hline Sunflower oil & 1.4 & 1.4 & 1.4 & 1.4 & 1.4 & 1.4 \\
\hline Yeast & 2.8 & 2.8 & 2.8 & 2.8 & 2.8 & 2.8 \\
\hline Calcium caseinate & - & 2 & - & 1 & 1.3 & 0.7 \\
\hline Calcium citrate & - & - & 2 & 1 & 0.7 & 1.3 \\
\hline Water & 44.4 & 44.4 & 44.4 & 44.4 & 44.4 & 44.4 \\
\hline
\end{tabular}

to room temperature $(2 \mathrm{~h})$. Then, loaves were packed in a clip-on polyethylene bag and stored $24 \mathrm{~h}$ at room temperature for quality, texture and sensory analysis.

\section{Bread evaluation}

In order to determine the bread quality, three loaves of bread from each group were analysed. Measurements were performed $24 \mathrm{~h}$ after baking. Loaf weight (using a digital balance with $0.01 \mathrm{~g}$ accuracy), volume (millet seeds displacement method) and a height/width ratio of the central slices were evaluated. The specific volume and bake loss, defined as the amount of water and organic material lost during baking, were calculated.

The instrumental measurement of the bread crumb and crust colour was quantified using a HunterLab ColorFlex (Hunter Associates Laboratory, Inc, Virginia, USA), and the results were expressed in accordance with the CIELAB system with reference to illuminant D65 and a visual angle of $10^{\circ}$. The measurements were performed through a 3-cm-diameter diaphragm containing an optical glass. The parameters determined were $L(L=0$ [black] and $L=100$ [white]), $a$ ( $-a=$ greenness and $+a=$ redness $), b(-b=$ blueness and $+b=$ yellowness). Values were the mean of ten replicates.

\section{Chemical composition}

Basic chemical composition was estimated in freeze-dried gluten-free breads. Ash [27] and total proteins content (estimated by calculating total nitrogen using Kjeldahl method and multiplied by factors 6.25) was determined [27].

The measurement of calcium content was carried out using the atomic absorption spectroscopy (AAS) method by a Unicam 939 spectrometer equipped with data basis ADAX, background correction and cathode lamps. Before determination all samples were wet mineralised with a mixture of acids: nitric and perchloric (3:1).
Texture properties

Texture properties of crumbs were measured using compression device of Instron 1011 (Instron Ltd, High Wycombe, England). The crumb samples of bread $(2.0 \times$ $2.0 \times 2.0 \mathrm{~cm}$ ) were compressed until fracture at crosshead speed $20 \mathrm{~mm} / \mathrm{min}$. In the examined experimental glutenfree breads, it was not possible to determine the texture parameters typical for common bread because its structure was destroyed at a very low strain i.e. about $20 \%$, whereas the standard strain of traditional double compression is 70-80\%. Thus, the parameters of fracture point i.e. fracture stress $F_{\mathrm{f}}(\mathrm{kPa})$, strain $D_{\mathrm{f}}(\%)$, and volume energy of fracture $E_{\mathrm{v}}(\mathrm{kPa})$ describing the resistance to compression of bread crumb were accepted as a measure of structure changes. Eight replicates were made for each loaf.

Sensory evaluation

\section{Sensory methods and evaluation conditions}

Quantitative descriptive analysis (QDA) was used to determine differences in the sensory characteristics of the breads $[28,29]$. Prior to the analysis, vocabularies of the sensory attributes were developed by the panel in a round-table session, using a standardised procedure [30]. Fourteen attributes related to the appearance, odour, taste and texture of breads were selected and thoroughly defined for profiling. Definitions and description of these sensory attributes are summarised in Table 2. The panellists evaluated the intensity perceived for each sensory attribute on unstructured graphical scales. The scales were $10 \mathrm{~cm}$ long and verbally anchored at each end, and the results were converted to numerical values (from 0 to 10 units) by a computer. Loaves were sliced (15 mm thickness) and served to the assessors in transparent plastic boxes. The samples were coded with a three-digit number and presented to the panellists in random order. Mineral water was offered between the samples. 
Table 2 Definitions of sensory attributes used for sensory evaluation of the gluten-free bread crumb by QDA analysis

\begin{tabular}{|c|c|}
\hline Attribute & Definition \\
\hline \multicolumn{2}{|l|}{ Appearance } \\
\hline Porosity & Visual impression of the size of the bread crumb porous (small-big) \\
\hline \multicolumn{2}{|l|}{ Odour } \\
\hline Acidulous & The intensity of the acidulous odour (none-very intensive) \\
\hline Sweet & Odour characteristic to sweet cakes (none-very intensive) \\
\hline Butterbread & Odour characteristic to sweet bun (none-very intensive) \\
\hline Yeast & Odour characteristic to yeast-raised bread produced from wheat flour (none-very intensive) \\
\hline \multicolumn{2}{|l|}{ Taste } \\
\hline Acidulous & The intensity of the acidulous taste (none-very intensive) \\
\hline Sweet & Basic taste illustrated by sucrose diluted in water $1.5 \%$ (none-very intensive) \\
\hline Butterbread & Taste characteristic to sweet bun (none-very intensive) \\
\hline Aftertaste & Aftertaste which continued after the removal of sample (none-very intensive) \\
\hline \multicolumn{2}{|c|}{ Texture (by finger) } \\
\hline Springiness & Degree of springiness in bread crumb by pressing with finger (not springy-springy) \\
\hline Elasticity & Response to stretching (not elastic-elastic) \\
\hline \multicolumn{2}{|c|}{ Texture (mouth feel) } \\
\hline Mastication & Degree of perceived resistance while chewing the sample 10 times (not mastic-mastic) \\
\hline Adhesiveness & Degree of adhesiveness perceived while chewing the sample 10 times (low-high) \\
\hline Moistness & Degree of moistness perceived while chewing the sample 10 times (dry-moist) \\
\hline
\end{tabular}

The assessments were carried out at a sensory laboratory room, which fulfils the requirements of the ISO standards [31]. The results were collected using a computerised system ANALSENS (IAR\&FR PAS, Olsztyn, Poland). Each sample was tested in two replications.

\section{Sensory panel}

Sensory assessments of the samples (QDA) were carried out by a panel consisting of 8 members ( 7 females and 1 male, ranging in age between 26 and 39 years) previously selected and trained according to ISO guidelines [32]. Prior to their participation in the experiments, the subjects were trained on sensory descriptors for gluten-free breads purchased from a local supermarket.

\section{Consumer test}

A semi-consumer panel of 30 members (including the Institute staff, graduate, and undergraduate students of the Institute) has made hedonic evaluation of the samples. In the test, each panellist was asked to assess the breads for overall quality, based on the overall colour, odour, taste and texture. An unstructured graphical scale was $10 \mathrm{~cm}$ long and anchored on both ends: disliked (0)-extremely liked (10).

\section{Statistical analysis}

The sensory attributes were analysed by ANOVA using Fisher's least significant difference test (LSD). Principal component analysis (PCA) was performed in order to describe the variance among all sensory data obtained. Statistical analyses were performed using software package (StatSoft Inc., v. 8.0, OK, USA). The statistical analysis of the texture results was carried out with a Statistica ver.5 (StatSoft, Inc., Tulsa, OK) software by using ANOVA with Duncan multiple range test (General Convention and Statistics, Statistica for Windows, 2nd Edition, Statsoft, Inc.).

\section{Results and discussion}

Among available calcium supplements, in the present study two organic calcium salts were applied, calcium citrate and calcium caseinate. Calcium citrate was chosen as a rich source of calcium ( $21.98 \%$, according to the manufacturer). The choice of calcium caseinate was based on its physicochemical specification (low lactose $0.38 \%$ and high protein $92.8 \%$ content, according to the manufacturer), and the beneficial influence on the sensory quality of glutenfree bread is shown in our preliminary studies.

Bread evaluation

Loaf specific volume, bake loss, height/width ratio of the slice, crumb and crust colour

The effect of individual and combined addition of both calcium salts on the technological parameters of gluten-free breads was analysed. All results obtained for specific 
Table 3 Technological parameters of the gluten-free breads containing calcium supplements

\begin{tabular}{|c|c|c|c|c|c|c|c|c|c|}
\hline \multirow[t]{2}{*}{ Sample } & \multirow{2}{*}{$\begin{array}{l}\text { Specific } \\
\text { volume }\left(\mathrm{cm}^{3} / \mathrm{g}\right)\end{array}$} & \multirow{2}{*}{$\begin{array}{l}\text { Bake } \\
\text { loss }(\%)\end{array}$} & \multirow{2}{*}{$\begin{array}{l}\text { Height/ } \\
\text { width ratio }\end{array}$} & \multicolumn{3}{|c|}{ Crust colour parameters } & \multicolumn{3}{|c|}{ Crumb colour parameters } \\
\hline & & & & $L^{*}$ & $a$ & $b$ & $L^{*}$ & $a$ & $b$ \\
\hline Control & $2.29 \mathrm{e}^{*}$ & $14.03 b$ & $0.65 b$ & $61.12 \mathrm{a}$ & $5.94 \mathrm{e}$ & $21.10 \mathrm{e}$ & $66.83 b$ & $2.49 \mathrm{~b}$ & $12.80 \mathrm{a}$ \\
\hline CAS & $2.34 \mathrm{e}$ & $12.92 \mathrm{~b}$ & $0.74 \mathrm{ab}$ & $58.31 \mathrm{bc}$ & $15.48 b$ & $33.34 \mathrm{~b}$ & $71.98 \mathrm{a}$ & $2.77 \mathrm{a}$ & $13.04 \mathrm{a}$ \\
\hline CIT & $3.34 \mathrm{a}$ & $19.44 \mathrm{a}$ & $0.83 \mathrm{a}$ & $56.52 \mathrm{~cd}$ & $13.67 \mathrm{c}$ & $32.80 \mathrm{~b}$ & $62.55 \mathrm{~d}$ & $2.08 \mathrm{c}$ & $11.73 b$ \\
\hline CAS1/CIT1 & $2.68 \mathrm{c}$ & $14.03 b$ & $0.74 \mathrm{ab}$ & $49.32 \mathrm{e}$ & $18.18 \mathrm{a}$ & $37.65 \mathrm{a}$ & $64.24 \mathrm{c}$ & $2.13 \mathrm{c}$ & $11.94 \mathrm{~b}$ \\
\hline CAS1.3/CIT0.7 & $2.49 \mathrm{~d}$ & $13.47 \mathrm{~b}$ & $0.73 \mathrm{ab}$ & $56.42 \mathrm{~d}$ & $13.37 \mathrm{c}$ & $30.89 \mathrm{c}$ & $66.35 b$ & $2.47 \mathrm{~b}$ & $12.80 \mathrm{a}$ \\
\hline CAS0.7/CIT1.3 & $2.96 \mathrm{~b}$ & $14.03 b$ & $0.81 \mathrm{a}$ & $59.32 \mathrm{ab}$ & $10.27 \mathrm{~d}$ & $28.31 \mathrm{~d}$ & $62.97 \mathrm{~d}$ & $2.10 \mathrm{c}$ & $11.95 \mathrm{~b}$ \\
\hline
\end{tabular}

* Values labelled with different letters in the same column are significantly different $(p<0.05)$. CAS bread fortified with $2 \%$ calcium caseinate, CIT bread fortified with $2 \%$ calcium citrate, CAS1/CIT1 bread fortified with $1 \%$ calcium caseinate and $1 \%$ calcium citrate, CAS1.3/CITO.7 bread fortified with $1.3 \%$ calcium caseinate and $0.7 \%$ calcium citrate, CASO.7/CIT1.3 bread fortified with $0.7 \%$ calcium caseinate and $1.3 \%$ calcium citrate

volume, bake loss, height/width ratio of the slice, and crumb and crust colour are shown in Table 3. Calcium fortification of gluten-free bread affected all quality characteristics tested. The addition of calcium caseinate alone did not influence significant change in the specific volume of bread CAS, comparing with the control bread. Calcium caseinate is highly soluble and can be easily dispersed in an aqueous mixture; therefore, it may contest for water with starch granules during baking process. The lack of water available to starch, due to the presence of calcium caseinate, could decrease starch swelling and that may explain the poor specific volume of bread CAS. In the study of Gallager et al. [25], it was reported that 3\% inclusions of dairy ingredients reduced the volume of gluten-free bread, but an increase in the level of dairy ingredients led to recovery of the volume, with sodium caseinate performing the best. The use of calcium citrate in experimental breads produced a significant increase in the specific volume. In comparison with the control bread, in bread CIT the specific volume have risen by $50 \%$. In this case also the largest cells were formed, which indicates that the morphological characteristic of the cellular structure of the crumb (cell size, cell walls thickness) influence significantly its visual and physical texture [33]. The slight effect of calcium caseinate on the bread specific volume was significantly improved by its combination with calcium citrate. The increase in the specific volume in all breads fortified with both calcium supplements added together was proportional to the rising amount of calcium citrate. High amount of calcium provided with calcium citrate may be involved in maintaining the textural quality of bread since calcium ions form cross-links or bridges between free carboxyl groups of the pectin chains, resulting in strengthening of the cell wall [34]. High methoxyl pectins undergo gelatinisation by stacking of the methoxyl groups through hydrophobic interactions and hydrogen bonding, whereas low methoxyl pectin forms a network with divalent ions such as calcium [35]. The divalent ion forms a bridge between two carboxyl groups of galacturonic acid situated on separate pectin molecules, thereby forming junction zones between the pectin molecules.

Analysing bake loss, no significant differences between the control bread and calcium-containing gluten-free breads were observed, except for bread CIT. The addition of calcium citrate alone resulted in a significant increase in the amount of water and organic material lost during baking (19.44\%). Crumb morphology strongly affects the rate of transport of water [36], and a smaller pore size is expected to slow down moisture migration [37]. Besides, a larger number of connections between gas cells would give a faster transport of water. Van Dalen et al. [38] found that the number of connections of each gas cell increased with increased gas cell size. Therefore, such a high value of bake loss observed in the bread CIT results probably from the size of pores (Fig. 1c). The loaves obtained with the individual addition of calcium caseinate or calcium citrate showed higher height/width ratio of slices in comparison with the unfortified control. However, only in the case of breads fortified with high amount of calcium citrate (CIT and CAS0.7/CIT1.3), the increase in the height/width ratio of slice was significant.

The addition of calcium supplements affected the colour of crust and crumb of gluten-free breads. In most cases, significant differences were observed between unfortified control and the fortified samples as well as among all gluten-free breads with different calcium level. Regarding the crust colour, the highest values of lightness $(L)$ were observed in the control bread. The light-coloured crust of the unfortified control was perceived as unappealing; therefore, the darkening of crust observed in all calcium-supplemented gluten-free breads was presumed as beneficial and desirable. The crust of gluten-free bread containing equal amounts of calcium caseinate and calcium citrate (CAS1/CIT1) was characterised by the lowest $L$ value. This is probably due to Maillard browning 


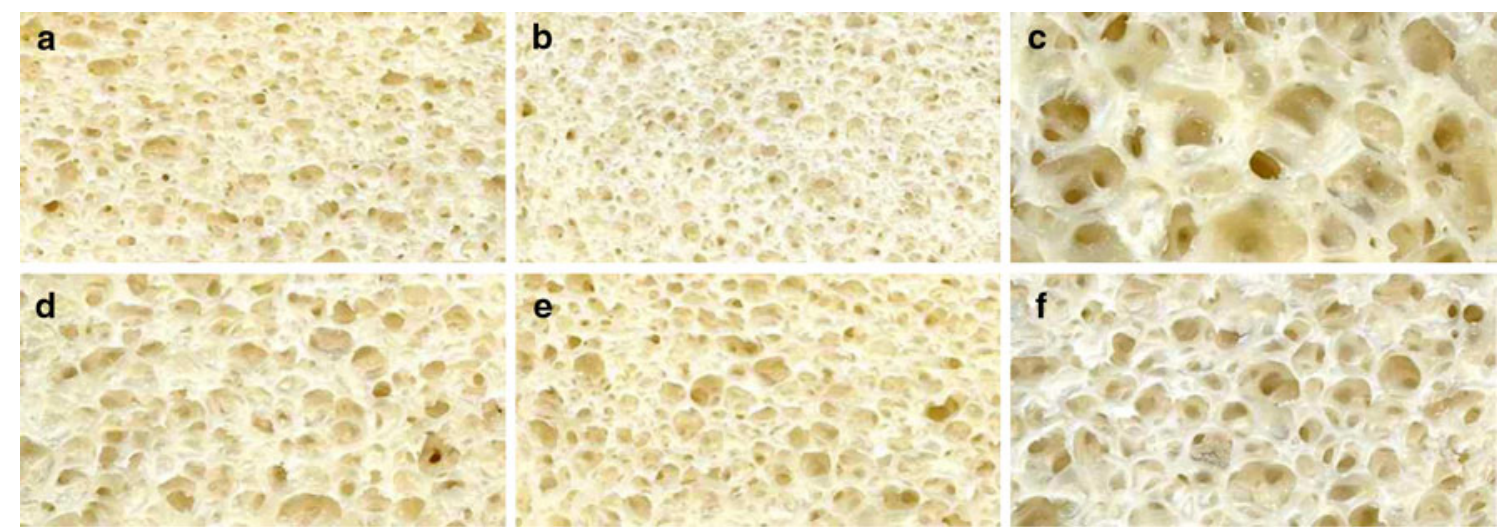

Fig. 1 Images of the crumb of gluten-free breads. a Unfortified control, b $C A S$ fortified with $2 \%$ calcium caseinate, c CIT fortified with $2 \%$ calcium citrate, d CAS1/CIT1 fortified with $1 \%$ calcium

Table 4 Proteins, ash and calcium content in gluten-free breads containing calcium supplements

\begin{tabular}{llll}
\hline Sample & $\begin{array}{l}\text { Proteins } \\
(\% \text { d.m. })\end{array}$ & $\begin{array}{l}\text { Ash } \\
(\% \text { d.m. })\end{array}$ & $\begin{array}{l}\text { Calcium } \\
(\mathrm{mg} / 100 \mathrm{~g})\end{array}$ \\
\hline Control & $0.46 \mathrm{~d}^{*}$ & $0.78 \mathrm{e}$ & $22.2 \mathrm{e}$ \\
CAS & $1.12 \mathrm{a}$ & $0.91 \mathrm{~d}$ & $46.5 \mathrm{~d}$ \\
CIT & $0.56 \mathrm{bcd}$ & $1.43 \mathrm{a}$ & $469.3 \mathrm{a}$ \\
CAS1/CIT1 & $0.77 \mathrm{bc}$ & $1.20 \mathrm{bc}$ & $267.5 \mathrm{bc}$ \\
CAS1.3/CIT0.7 & $0.82 \mathrm{~b}$ & $1.10 \mathrm{c}$ & $194.9 \mathrm{c}$ \\
CAS0.7/CIT1.3 & $0.63 \mathrm{~cd}$ & $1.31 \mathrm{~b}$ & $315.3 \mathrm{~b}$
\end{tabular}

* Values labelled with different letters in the same column are significantly different $(p<0.05)$. CAS bread fortified with $2 \%$ calcium caseinate, CIT bread fortified with $2 \%$ calcium citrate, CAS1/CIT1 bread fortified with $1 \%$ calcium caseinate and $1 \%$ calcium citrate, CAS1.3/CIT0.7 bread fortified with $1.3 \%$ calcium caseinate and $0.7 \%$ calcium citrate, CASO.7/CIT1.3 bread fortified with $0.7 \%$ calcium caseinate and $1.3 \%$ calcium citrate

reactions where lysine residues from caseinate and glucose from starch are the reactants. The development of the non-enzymatic browning in food products and the nature of the compounds formed in the different stages of the Maillard reaction also depend on the presence of other reactive compounds in the food system: for example, mineral elements, especially metal ions with variable valence $[39,40]$. Calcium binds weakly to Maillard reaction products in model systems and the strength of banding occurred in the order $\mathrm{Mg}^{2+}>\mathrm{Cu}^{2+}=$ $\mathrm{Ca}^{2+}>\mathrm{Zn}^{2+}$ [41]. It is possible that such a mechanism might influence the rate of the non-enzymatic browning reaction in case of bread supplemented with both calcium salts. In all analysed crust samples, the values of parameter $a$ were positive (red hue). The incorporation of calcium supplements affected the significant increase in redness, especially in the case of bread CAS1/CIT1, where the $a$ values were three times higher than in the caseinate and $1 \%$ calcium citrate, e CAS1.3/CITO.7 fortified with $1.3 \%$ calcium caseinate and $0.7 \%$ calcium citrate, f CASO.7/CIT1.3 fortified with $0.7 \%$ calcium caseinate and $1.3 \%$ calcium citrate

control. Also the $b$ values of the crust were all positive (yellow hue). The individual addition of each analysed calcium salt at $2 \%$ supplementation level (CAS or CIT) produced a significant increase in the value of that parameter. However, similarly to the redness, the highest score was observed in bread with the combined addition of both calcium sources at equal amount. Gallagher et al. [25] analysing gluten-free breads supplemented with dairy powders reported that breads containing high protein/low lactose powders (sodium caseinate, milk protein isolates) had an appealing dark crust and white crumb appearance, and received good acceptability scores in sensory tests. Similarly, in the recent study by Nunes et al. [42], the incorporation of dairy powders improves the colour of the bread crust. The application of calcium supplements produced fine-coloured crust of examined breads. From the technological point of view, the formation of MRPs and melanoidins is important for the formation of flavour, colour and texture of baking products [43, 44].

Crumb colour was differently influenced by analysed calcium supplements (Table 3; Fig. 1). Gluten-free bread with calcium caseinate alone (CAS) was characterised by the lightest crumb. The colour of calcium caseinate (white and cream-coloured powder) may also confer the light colour of that bread crumb. The opposite effect was observed when calcium citrate was incorporated to the gluten-free formulation. When the mixture of both calcium supplements was added, the $L$ value increased with the rising amount of calcium caseinate. The $a$ and $b$ values for the crumbs were all positive. The single addition of calcium caseinate significantly increased the crumb redness, and conversely, calcium citrate produced its reduction. High amount of calcium caseinate (2 and 1.3\%) in bread did no affect the intensity of yellow hue which was similar to the unfortified control, whereas the 
addition of calcium citrate produced a significant decrease in this parameter.

\section{Chemical composition}

Total proteins and mineral compounds content was estimated in freeze-dried gluten-free breads. As it was predicted, the supplementation of gluten-free formulation with calcium caseinate, rich in proteins $(92.8 \%$ d.m.), increased the total proteins content in supplemented breads (Table 4). Bread CAS was two times richer in proteins than unfortified control and bread CIT supplemented with calcium citrate nevertheless, protein content in this bread was still quite low. The commercial Polish gluten-free formulas
NISKOBIAŁKOWA and MLECZNA were characterised by a similar low content of proteins, near $1.5 \%$ d.m. [45, 46]. Generally, gluten-free breads obtained from mixing starches or gluten-free flour are poor in proteins $[9,25]$. In breads fortified with both calcium supplements together, the proteins content increased systematically with the rising amount of calcium caseinate. The mineral compounds content in analysed gluten-free breads was significantly dependent on the level of calcium citrate supplementation. The minerals content in bread CIT was predominant.

The addition of calcium salts to analysed gluten-free dough increased significantly the calcium content in the gluten-free breads (Table 4). Bread CIT was more than twenty times richer in calcium in comparison with the
Fig. 2 Differences in texture properties between upper and bottom layers of crumbs of gluten-free breads
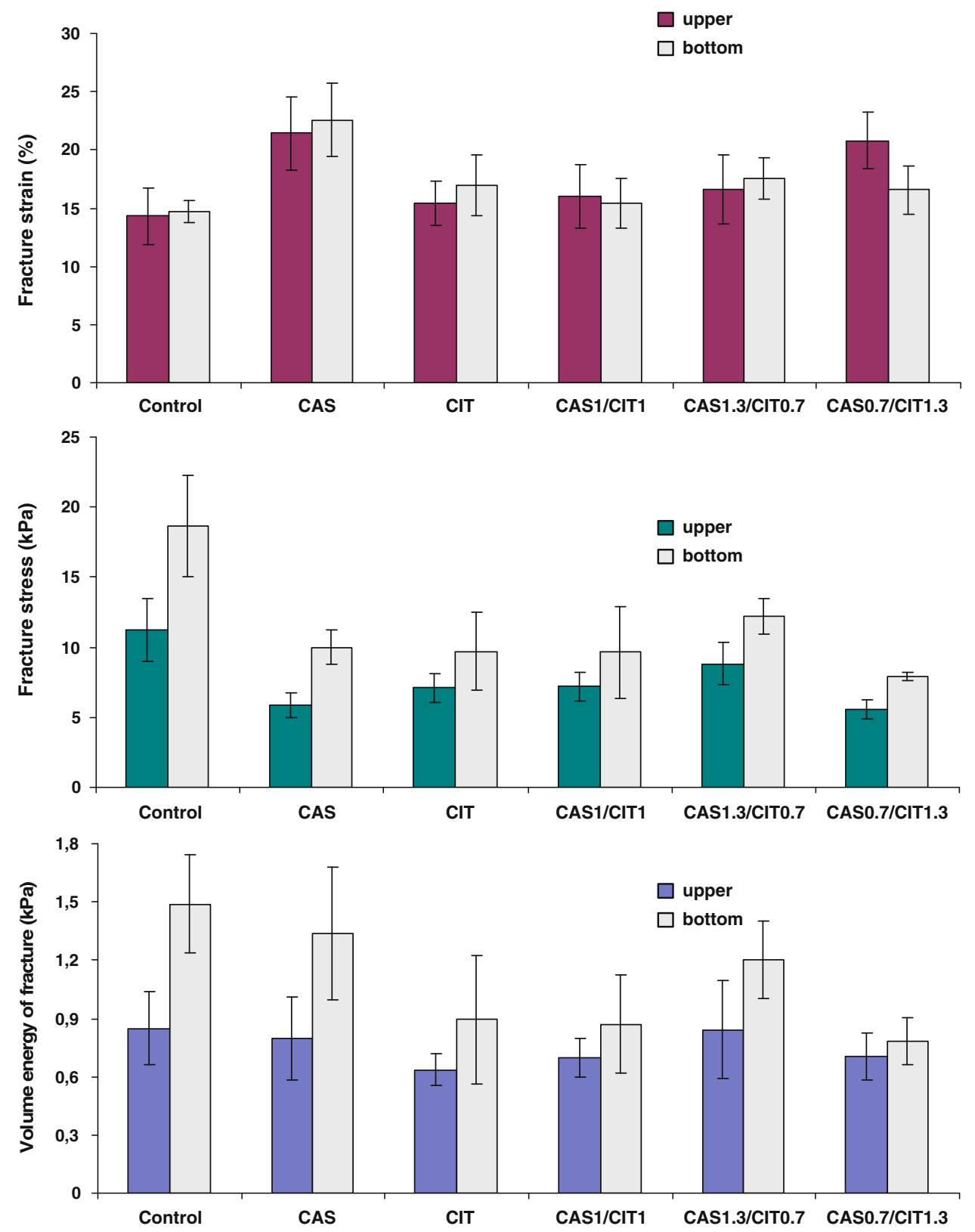
control bread and ten times richer than bread supplemented with calcium caseinate alone. In breads containing both calcium supplements, the calcium content increased proportionally to the rising amount of calcium citrate. Good food sources contain approx. 100-190 mg of calcium and contribute at least $10-19 \%$ of the daily value of the US RDA (recommended daily or dietary, allowance or amounts) for calcium in a selected serving size [47]. Therefore, examined gluten-free breads containing high amount of calcium citrate could be considered as a good source of calcium providing approx. 100-140 mg of calcium per serving. The WHO [48] recommended calcium allowances (mg/day) which were based on UK, European Union, and American and Canadian data as follows: children, 1-3 years: 500; 4-6 years: 600; 7-9 years: 700; adolescents, 10-18 years: 1300; adults: female: 19 years to menopause: 1,000; post-menopause: 1,300; males: 19-65 years: 1,000; 65+: 1,300. A number of foods are

Table 5 Texture properties of crumb of gluten-free breads containing calcium supplements

\begin{tabular}{llcl}
\hline Sample & $D_{\mathrm{f}}(\%)$ & $\sigma_{\mathrm{f}}(\mathrm{kPa})$ & $E_{\mathrm{v}}(\mathrm{kPa})$ \\
\hline Control & $14.5 \mathrm{a}^{*}$ & $14.2 \mathrm{c}$ & $1.11 \mathrm{~b}$ \\
CAS & $22.0 \mathrm{c}$ & $7.9 \mathrm{ab}$ & $1.07 \mathrm{ab}$ \\
CIT & $16.2 \mathrm{ab}$ & $8.4 \mathrm{ab}$ & $0.76 \mathrm{a}$ \\
CAS1/CIT1 & $15.7 \mathrm{ab}$ & $8.4 \mathrm{ab}$ & $0.78 \mathrm{a}$ \\
CAS1.3/CIT0.7 & $17.0 \mathrm{ab}$ & $10.5 \mathrm{~b}$ & $1.02 \mathrm{ab}$ \\
CAS0.7/CIT1.3 & $18.4 \mathrm{~b}$ & $6.7 \mathrm{a}$ & $0.72 \mathrm{a}$ \\
\hline
\end{tabular}

* Values labelled with different letters in the same column are significantly different $(p<0.05) . D_{f}$, fracture strain; $F_{\mathrm{f}}$, fracture stress; $E_{\mathrm{v}}$, volume energy of fracture. $C A S$ bread fortified with $2 \%$ calcium caseinate, CIT bread fortified with $2 \%$ calcium citrate, CAS1/CIT1 bread fortified with $1 \%$ calcium caseinate and $1 \%$ calcium citrate, CAS1.3/CIT0.7 bread fortified with $1.3 \%$ calcium caseinate and $0.7 \%$ calcium citrate, CASO.7/CIT1.3 bread fortified with $0.7 \%$ calcium caseinate and $1.3 \%$ calcium citrate fortified with calcium. In Poland, it is allowed to enrich flour and cereal products in calcium up to $3 \mathrm{~g} / \mathrm{kg}$ of product using mainly calcium carbonate [49]. According to the US enrichment standards, flour can be fortified to contain $211 \mathrm{mg}$ of $\mathrm{Ca} / 100 \mathrm{~g}$ [50]. Ranhotra et al. [51, 52] have shown that flour can be fortified to contain $\mathrm{Ca}$ at much higher levels than US standard without adversely affecting white bread quality, and this $\mathrm{Ca}$ is well absorbed and retained. Generally, gluten-free breads and baked products are poor in calcium [49]; therefore, the addition of calcium at appreciably high levels to such products could contribute to a significant increase in calcium amount in the diet of celiac patients.

Texture characteristics of bread crumb

Distinct differences of fracture stress and energy values, which can be accepted as indices expressing crumb hardness, between the upper and the bottom part of the experimental gluten-free breads were found (Fig. 2).

These parameters were always higher in the case of bottom part. Similarly, our earlier studies on gluten-free bread containing bean starch [9] revealed distinct differences between the bottom (harder) and upper (softer) part of bread slice. The evaluation of the mechanical properties of bread crumb is difficult as bread crumb has a complex cellular structure, besides the distribution of cells within the bread crumb is not homogenous. The differences in texture properties between upper and bottom part of examined gluten-free bread slices could be influenced by the differences in the thickness of the cell walls and the moisture content [33]. Differences in fracture strain values (related to crumb elasticity) for these parts of crumbs were smaller than standard deviation calculated for particular breads, except for bread CAS0.7/CIT1.3. To evaluate the quality of whole bread structure, the average values of the
Fig. 3 Overall preferences of gluten-free bread. Bars labelled with different letters are significantly different $(p \leq 0.05)$. CAS bread fortified with $2 \%$ calcium caseinate, $C I T$ bread fortified with $2 \%$ calcium citrate, CAS1/CIT1 bread fortified with $1 \%$ calcium caseinate and $1 \%$ calcium citrate, CAS1.3/CITO.7 bread fortified with $1.3 \%$ calcium caseinate and $0.7 \%$ calcium citrate, CASO.7/CIT1.3 bread fortified with $0.7 \%$ calcium caseinate and $1.3 \%$ calcium citrate

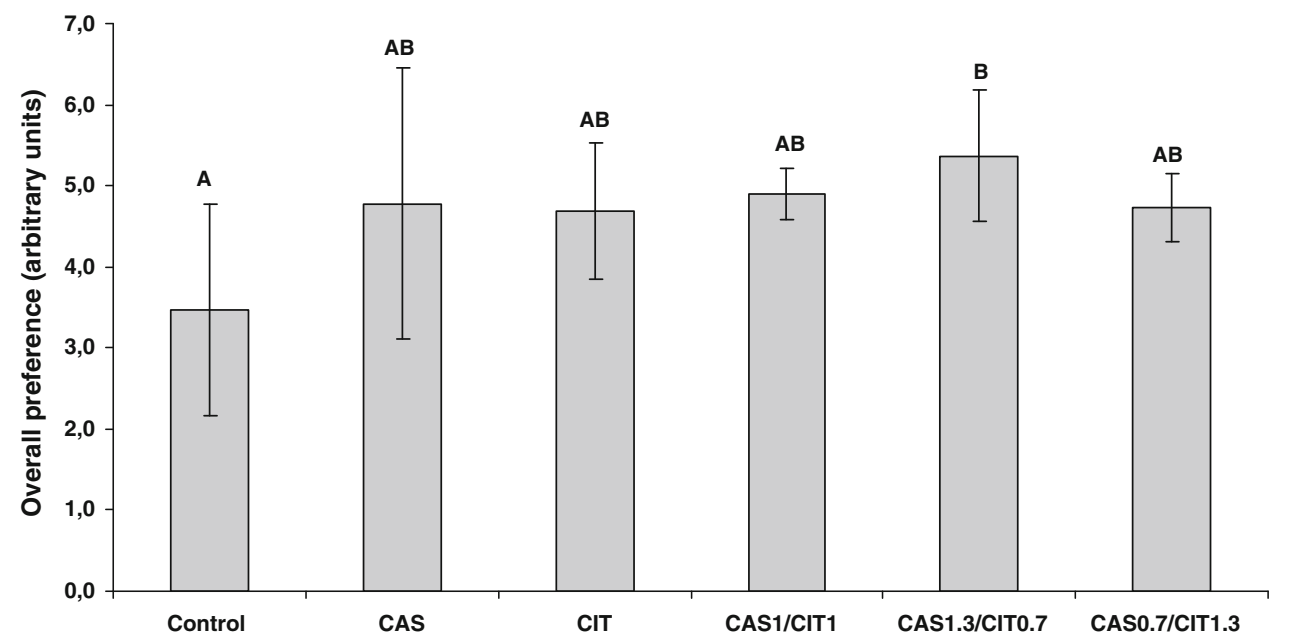


mechanical resistance parameters of experimental glutenfree bread crumbs were calculated (Table 5).

Both control and supplemented breads, independently of the kind of calcium salt added, were rather crumbly that resulted from the absence of gluten proteins. Control bread was characterised by the lowest fracture strain values at the highest fracture stress and energy values. The variance analysis supplemented by Duncan multiple range test classified control bread to the separate uniform group. Among examined breads, crumb structure of bread CIT and CAS1/CIT1 was almost the same, showing the medium values of determined parameters. The addition of calcium caseinate alone (CAS) resulted in the highest elasticity $\left(D_{\mathrm{f}}=22.0 \%\right)$ at medium fracture stress and energy, which, according to results of statistical analysis, were similar to CIT and CAS1/CIT1 breads. On the other hand, in the case of bread CAS0.7/CIT1.3, the addition of both calcium supplements resulted in quite high elasticity $\left(D_{\mathrm{f}}=18.4 \%\right)$ and the lowest hardness $\left(\sigma_{\mathrm{f}}=6.7 \mathrm{kPa}\right)$ and statistical calculation allowed to place this bread also in separate uniform group. Thus, the distinct effect of addition of calcium supplements alone and in combination on crumb structure (softer and more elastic than this of control bread) was confirmed. Although the differences in structure parameters between supplemented breads were usually statistically insignificant, the recommendation of the best calcium supplementation for improving of crumb texture was possible. Stathopoulos and O'Kennedy [11] advanced thesis that by increasing calcium concentration to an optimum level in the casein/caseinate ingredient it will be possible, under the correct $\mathrm{pH}$ and ionic strength conditions, to replace $\mathrm{S}-\mathrm{S}$ bonds that govern the properties of gluten in a wheat dough with $\mathrm{Ca}$ (coordination) links. They confirmed the important role of calcium in creation of structure of gluten-free breads and found concentrated casein systems containing $30 \mathrm{mg} \mathrm{Ca} / \mathrm{g}$ protein as the most suitable for gluten substitution. In presented work, correlations between calcium content and fracture strain $(R=-0.7275)$ and volume energy of fracture $(R=$ $-0.8325)$ were found, whereas there was no correlation between calcium content and fracture stress $(R=$ $-0.1672)$. Obtained results were dissimilar to these presented by Stathopolos and O'Kennedy [11] probably due to the lack of adequate amount of proteins in examined calciumfortified breads. Therefore, it was impossible to obtain an aggregated calcium-caseinate product what could emulate the textural properties of gluten.

\section{Sensory evaluation}

The effects of the calcium caseinate and calcium citrate on the overall preference of gluten-free bread are shown in Fig. 3. The results indicated that palatability of the bread

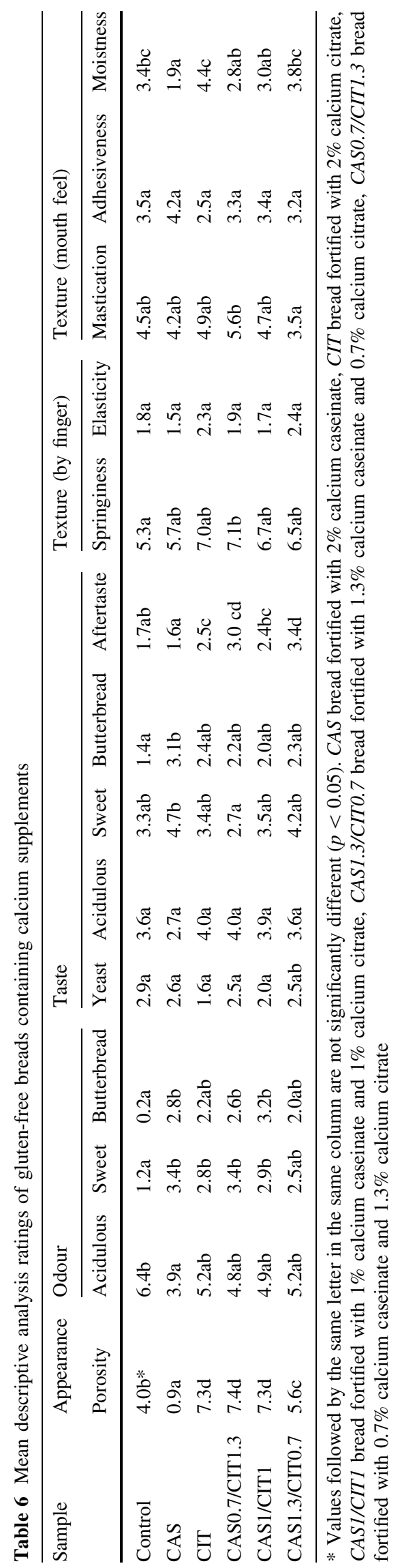



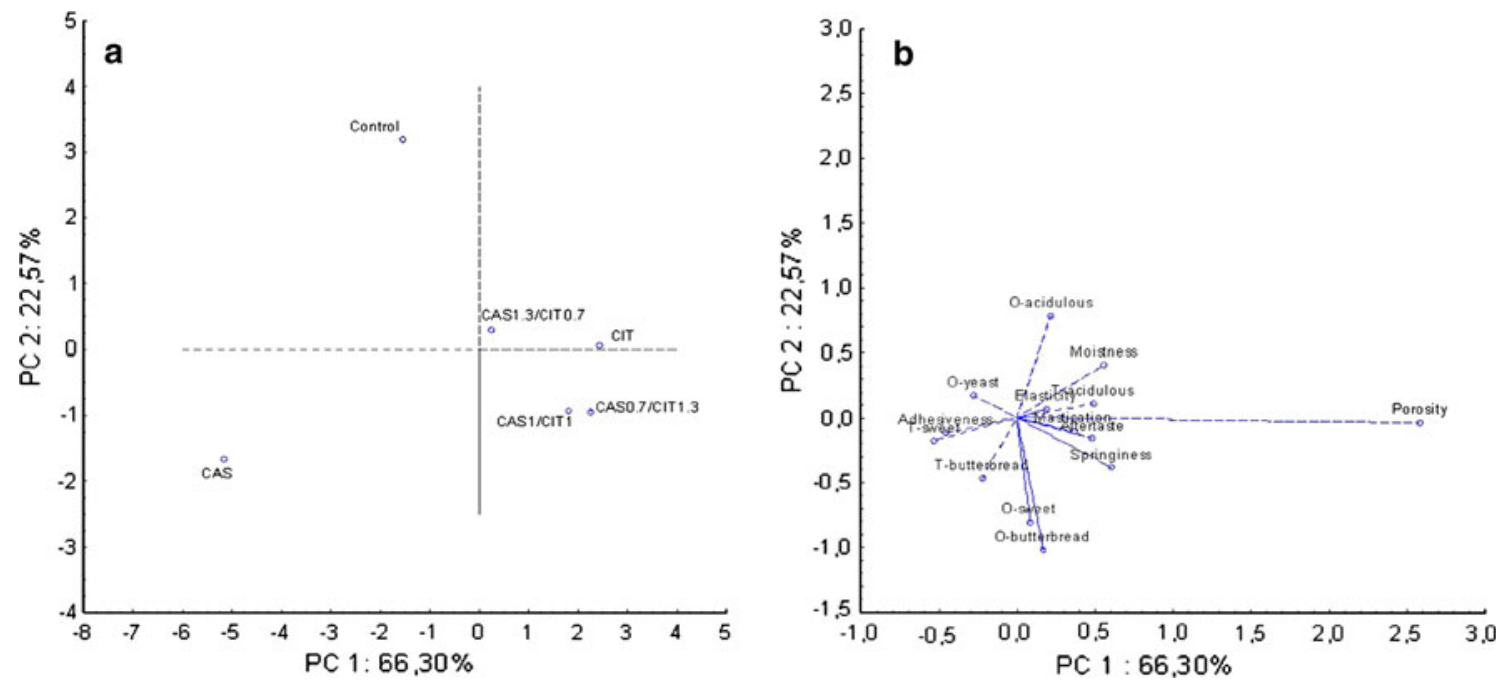

Fig. 4 Principal component analysis $(P C A)$ scores (a) and loadings (b) of sensory data for gluten-free breads

supplemented with calcium was significantly higher $(p \leq 0.05)$ then those of the unfortified control. The average overall preference of scores (in the scale of 10 units) for bread supplemented with calcium ranged from 4.7 units (CIT and CAS0.7/CIT1.3) to 5.4 units (CAS1.3/CIT0.7), whereas the control obtained 3.6 units. It indicates that calcium caseinate and calcium citrate might contribute to improve the sensory properties of gluten-free bread.

To find attributes which influenced the sensory quality of gluten-free breads quantitative descriptive analysis (QDA) was used. This method is often applied to study a variety of cereal products [53-55]. The QDA procedure elicited 14 attributes as follows: one for appearance, four for odour, four for flavour/taste and five for texture (by finger and mouth feel).The mean sensory ratings for the samples and the analysis of variance are presented in Table 6. The results show highly significant differences $(p \leq 0.001)$ in the intensity of attributes such as porosity, aftertaste and springiness caused by the type of breads. The samples containing calcium caseinate and calcium citrate at all levels (except CAS sample) were scored higher for porosity in comparison with the control bread. In other words, the density of gluten-free bread supplemented with calcium decreased. It should be emphasised that the desirable for the consumer sensory attributes such as the sweet odour, butterbread odour, "butterbread" taste as well as springiness of breads increased with the addition of calcium caseinate and calcium citrate.

In order to observe the differences in the analysed samples more clearly, principal component analysis (PCA) was performed. This method allows to see a graphic representation of the data so the variation between the samples can be more easily interpreted. The data obtained from
QDA method (14 attributes and 5 products) were subjected to PCA which was performed on the covariance matrix of the samples with no rotation. Two principal components were extracted which had eigen values greater than one (29,813 and 5,148, respectively). The first two principal components (PC1 and $\mathrm{PC} 2$ ) which together explained $88.87 \%$ of the total variance were plotted in Fig. 4a and $\mathrm{b}$.

PC1 explained the majority of the variations, comprising $66.30 \%$, while $22.57 \%$ was due to PC2. The scores of the PC1 and PC2, for gluten-free breads are presented in Fig. 4a. It can be seen that PCA technique differentiated the samples by type of breads which formed distinctly separate cluster found along the first and second principal component. The control and CAS sample were located oppositely to CAS; CAS1/CIT1; CAS1.3/CIT0.7and CAS0.7/CIT1.3 samples on the PCA chart which indicated their different sensory characteristics. The distribution of sensory attributes in space defined by the first and second PCA dimensions is presented in Fig. 4b. The attributes: acidulous taste, porosity, springiness and adhesiveness had a high loading $(>0.8)$ in PC1. Thus, these attributes had a decisive effect on the variation in the sensory quality of the samples. The second PC was associated with the attributes such as acidulous odour, sweet odour, butterbread odour and butterbread taste. However, it should be stressed that the vector describing the acidulous odour of the samples was located opposite to the vectors describing sweet odour, butterbread odour and butterbread taste on the PCA chart. This implies a negative correlation between the notes. Taken collectively, sensory results (QDA and PCA) proved that the addition of calcium caseinate and calcium citrate to samples altered the sensory quality of gluten-free breads. 


\section{Conclusions}

The application of organic calcium salts, calcium caseinate and calcium citrate influenced favourably the baking characteristic of experimental gluten-free breads. Calcium citrate improved the specific volume of gluten-free breads, while the mixture of both calcium supplements in formulations produced fine-coloured bread crust. Significant enrichment in calcium was obtained in breads with 2 and $1.3 \%$ calcium citrate addition; therefore, they could be considered as a good source of calcium. All calcium-fortified breads, regardless the kind and amount of calcium salt added, were rather crumbly; however, they were softer and more elastic in comparison with unfortified control. Consumers perceived the appearance and sensory quality of calciumsupplemented gluten-free breads as desirable. This result suggests that applied organic calcium salts can be used successfully in gluten-free recipes in order to obtain goodquality and rich in calcium gluten-free bread.

Acknowledgments The research was partly supported by a grant NN312 345033 of the Ministry of Science and Higher Education (2007-2011). The authors would like to thank to Dr Jadwiga Sadowska from the Department of Chemistry and Physical Properties of Food, IAR\&FR for the texture analysis and the advice given regarding the analysis of obtained results. The authors declare that there are no conflicts of interest to disclose.

Open Access This article is distributed under the terms of the Creative Commons Attribution Noncommercial License which permits any noncommercial use, distribution, and reproduction in any medium, provided the original author(s) and source are credited.

\section{References}

1. Fasano A, Berti I, Gerarduzzi T, Not T, Colletti RB, Drago S, Elitsur Y, Green PH, Guandalini S, Hill ID, Pietzak M, Ventura A, Thorpe M, Kryszak D, Fornaroli F, Wasserman SS, Murray JA, Horvath K (2003) Arch Intern Med 163:286-292

2. Tommasini A, Not T, Kiren V, Baldas V, Santon D, Trevisiol C, Berti I, Neri E, Gerarduzzi T, Bruno I, Lenhardt A, Zamuner E, Spanò A, Crovella S, Martellossi S, Torre G, Sblattero D, Marzari R, Bradbury A, Tamburlini G, Ventura A (2004) Arch Dis Child 89:512-515

3. Sampson M, Zhang L, Yazdi F, Mamaladze V, Pan I, McNeil J, Mack D, Patel D, Moher D (2005) Gastroenterol 128:57-67

4. Ciacci C, Cirillo M, Cavallaro R, Mazzacca G (2002) Digestion 66:178-185

5. Pietzak MM (2005) Gastroenterol 128:135-141

6. Arendt EK, O'Brien CM, Schober T, Gormley TR, Gallagher E (2002) Farm Food 12:21-27

7. Rosell CM, Rojas J, Benedito de Barber C (2001) Food Hydrocoll $15: 75-81$

8. Lazaridou A, Duta D, Papageorgiou M, Belc N, Biliaderis CG (2007) J Food Eng 79:1033-1047

9. Krupa U, Rosell CM, Sadowska J, Soral-Śmietana M (2010) J Food Process Preserv 34:501-518
10. Alvarez-Jubete L, Auty M, Arendt EK, Gallagher E (2010) Eur Food Res Technol 230:437-445

11. Stathopoulos C, O'Kennedy BT (2008) Int J Dairy Technol 61:397-402

12. Moroni AV, Dal Bello F, Arendt EK (2009) J Food Microbiol 26:676-684

13. Kupper C (2005) Gastroenterol 128:121-127

14. Thompson T, Denis M, Higgins LA, Lee AR, Sharrett MK (2005) J Hum Nutr Diet 18:163-169

15. Selby PL, Davies M, Adams JE, Mawer EB (1999) J Bone Miner Res 14:652-657

16. Meyer D, Stavropolous S, Diamond B, Shane E, Green PH (2001) Am J Gastroenterol 96:112-119

17. Martin BR, Weaver CM, Heaney RP, Packard PT, Smith DL (2002) J Agric Food Chem 50(13):3874-3876

18. Cumming RG, Cummings SR, Nevitt MC, Scott J, Ensrud KE, Vogt TM (1997) Am J Epidemiol 145:926-934

19. Domrongkitchaiporn S, Ongphiphadhanakul B, Stitchantrakul W, Piaseu N, Chansirikam S, Puavilai G, Rajatanavin R (2000) Osteoporos Int 11(6):486-492

20. O'Connell MB, Stamm PL (2004) Clin Rev Bone Mineral Metab 2(4):357-371

21. Thomas SDC, Reed AG, Tucker G, Slobodan P, O'Loughlin PD, Nordin BEC (2008) Calcif Tissue Int 83:81-84

22. Tondapu P, Provost D, Adams-Huet B, Sims T, Chang C, Sakhaee K (2009) Obes Surg 19(9):1256-1261

23. O'Connell MB, Madden DM, Murray AM, Heaney RP, Kerzner LJ (2005) Am J Med 118:778-781

24. Kenny S, Wehrle K, Stanton C, Arendt EK (2000) Eur J Food Res Technol 210:391-396

25. Gallagher E, Gormley TR, Arendt EK (2003) J Food Eng 56:153-161

26. Krupa U, Soral-Śmietana M, Wronkowska M (2008) Gluten-free mixture. Patent application P 386253

27. AOAC (1990) Official method 976.06. In: Williams S (ed) Official methods of analysis of AOAC International, 15th edn, Arlington

28. Stone H, Sidel JL (1993) Sensory evaluation practices, 2nd edn. Academic Press, San Diago

29. Lawless HT, Heymann H (1999) Sensory evaluation of food: principles and practices. Chapman and Hall, New York

30. ISO/DIS 13299:1998 Sensory analysis-methodology-general guidance for establishing a sensory profile

31. ISO 8589:1998 Sensory analysis-general guidance for the design of test rooms

32. ISO 8586-1:1993 Sensory analysis—general guidance for the selection, training and monitoring of assessors-Part 1: selected assessors

33. Scanlon MG, Zghal MC (2001) Food Res Int 34:841-864

34. Garcia JM, Herrera S, Morilla A (1996) J Agr Food Chem 44:30-33

35. Powell DA, Morris ER, Gidley MJ, Rees DA (1982) J Mol Biol 155:517-531

36. Roca E, Guillard V, Guilbert S, Gontard N (2006) J Cereal Sci 43:144-151

37. Labbuza TP, Hyman CR (1998) Trends Food Sci Technol 9:47-55

38. van Dalen G, Notenboom P, van Vliet LJ, Voortman L, Esveld E (2007) Image Anal Stereol 26:169-177

39. Hayase F, Shibuya T, Sato J, Yamamoto M (1996) Biosci Biotechnol Biochem 60:820-825

40. Ramonaityte DT, Keršiene M, Adams A, Tehrani KA, de Kimpe N (2009) Food Res Int 42:331-336

41. O'Brien J, Morrissey PA (1997) Food Chem 58:17-27

42. Nunes MHB, Ryan LAM, Arendt EK (2009) Eur Food Res Technol 229:31-41 
43. Roda-Mendoza M, Garcia-Banos JL, Villamiel M, Olano A (2004) J Cereal Sci 39:167-173

44. Zieliński H, Michalska A, Ceglińska A, Lamparski G (2008) Eur Food Res Technol 226:671-680

45. Wronkowska M, Soral-Śmietana M (2008) Pol J Food Nutr Sci 58(1):59-63

46. Wronkowska M, Troszyńska A, Soral-Śmietana M, Wołejszo A (2008) Pol J Food Nutr Sci 58(2):211-216

47. Fishbain L (2004) Regul Toxicol Pharmacol 39:67-80

48. WHO (1998) Vitamin and mineral requirements in human nutrition: report of a joint FAO/WHO expert consultation, Bangkok

49. Gawęcki J, Hryniewiecki L (1998) Żywienie człowieka. Podstawy nauki o żywieniu. Wydawnictwo Naukowe PWN, Warszawa
50. FR C (1996) Enriched flour. Code of Federal Regulations 21 (part 137.170). GPO, Washington

51. Ranhotra GS, Gelroth JA, Leinen SD (1999) Cereal Chem 67:325-327

52. Ranhotra GS, Gelroth JA, Leinen SD (2000) Cereal Chem 77(3):293-296

53. Kilhlberg I, Johansson L, Kohler A, Risvik E (2004) J Cereal Sci 39:67-84

54. Heenan SP, Dufour J-P, Hamid N, Harvey W, Delahunty CM (2008) Food Res Int 41:989-997

55. Klensporf D, Jeleń H (2008) J Cereal Sci 48:656-661 